Check for updates

Cite this: J. Mater. Chem. A, 2020, 8 , 2637

Received 4th September 2019

Accepted 6th January 2020

DOI: 10.1039/c9ta09775a

rsc.li/materials-a

\section{Detecting structural transformation of cobalt phosphonate to active bifunctional catalysts for electrochemical water-splitting $\dagger$}

\author{
Arindam Indra, (iD ab Prashanth W. Menezes, (D) *b Ivelina Zaharieva, ${ }^{c}$ Holger Dau (D) *c \\ and Matthias Driess (iD *b
}

In recent years, several cobalt-based catalysts have been developed for water splitting because of their promising activity, stability and structural motifs. Here, we report that cobalt phosphonate represents a novel class of bifunctional single-source precursors for highly efficient alkaline electrochemical $\mathrm{O}_{2}$ evolution (OER) and $\mathrm{H}_{2}$ evolution reaction (HER). Inspired by its favorable catalytic OER and HER activity, an overall water-splitting device has been constructed from this precursor, showing very low cell voltage (1.62 $\mathrm{V}$ (a $10 \mathrm{~mA} \mathrm{~cm}{ }^{-2}$ ) and excellent long-term stability. Depending on the applied oxidation and reduction potential on cobalt phosphonate, two distinct modified structures at the anode and cathode have been uncovered employing the quasi in situ X-ray absorption spectroscopy and ex situ methods. During OER, the phosphonate precursor reorganized itself to layered $\mathrm{CoO}_{x}(\mathrm{OH})_{y}$ structure with defects and disorders, while the contribution of the metallic $\mathrm{Co}$ along with $\mathrm{CO}_{3} \mathrm{O}_{4}$ spinel and $\mathrm{Co}(\mathrm{OH})_{2}$ is evident to drive the HER. The presented work demonstrates the advantage of using the 'all-in-one' precursor approach to realize bifunctional water-splitting electrocatalysts through the evolution of different species with self-supporting interfacial structural features at the anode and cathode during electrochemical water splitting.
\end{abstract}

\section{Introduction}

Electrochemical energy conversion by splitting water into $\mathrm{O}_{2}$ and $\mathrm{H}_{2}$ may become pivotal in providing clean and sustainable energy replacing fossil fuels. ${ }^{1-3}$ The water-splitting process comprises of two half-cell reactions-oxygen evolution reaction (OER) at the anode and hydrogen evolution reaction (HER) at the cathode. ${ }^{4-6}$ Water splitting is a thermodynamically uphill reaction and electrolysis of water requires a huge amount of energy in terms of potential. ${ }^{5}$ Moreover, the $\mathrm{O}-\mathrm{O}$ bond formation during OER requires the removal of four electrons and four protons from two water molecules involving high-energy intermediates. ${ }^{7}$ Therefore, special attention has been provided to develop an efficient catalyst system for the overall water splitting reactions. ${ }^{\mathbf{2}}$

${ }^{a}$ Department of Chemistry, Indian Institute of Technology (BHU), Varanasi, Uttar Pradesh-221005, India

${ }^{b}$ Department of Chemistry: Metalorganics and Inorganic Materials, Technische Universität Berlin, Straße des 17 Juni 135, Sekr. C2, 10623 Berlin, Germany. E-mail: prashanth.menezes@mailbox.tu-berlin.de; matthias.driess@tu-berlin.de

${ }^{c}$ Fachbereich Physik, Freie Universität Berlin, Arnimallee 14, 14195 Berlin, Germany. E-mail: holger.dau@fu-berlin.de

$\dagger$ Electronic supplementary information (ESI) available: Characterization of the catalysts by spectroscopic, microscopic, PXRD and analytical techniques along with the details of the experimental and electrochemical techniques. See DOI: 10.1039/c9ta09775a
Although noble metal-based $\mathrm{RuO}_{2}$ and $\mathrm{IrO}_{2}$ catalysts produce high water oxidation activity and $\mathrm{Pt}$ is known for the excellent hydrogen evolution, scarcity and cost of these materials limit their use for large-scale applications. ${ }^{\mathbf{9 1 0}}$ Recently, first-row transition metal-based catalysts have been widely explored for the OER and HER. ${ }^{11-13}$ In this respect, cobalt-based materials are of particular importance because of their promising water-oxidation activity at reasonable overpotentials and regarding the understanding of structural and functional properties during water oxidation. ${ }^{\mathbf{1 4 - 1 7}}$ After the first report of in situ generated cobalt (oxide) phosphate (CoPi) catalyst for the efficient oxygen evolution in the neutral medium by Nocera and co-workers, ${ }^{\mathbf{1 8}, 19}$ several crystalline and amorphous cobalt phosphates and oxides have extensively been investigated for electrocatalytic OER. ${ }^{16,20-24}$ Most of the cobalt-based catalysts produce high electrochemical water oxidation activity in the alkaline medium through the activation of the catalyst into amorphous cobalt hydroxide-oxyhydroxide. ${ }^{16,25-27}$ In many cases, the transformation is limited to the surface of the particles to form an amorphous shell while complete amorphization of the particles has been observed for the ultra-small nanoparticles. ${ }^{24,26}$ Reversible amorphization of the catalytic species in cobalt oxide has also been demonstrated by some of us. ${ }^{15}$ Moreover, the coordination environment around the cobalt center and the local structure has also shown to control the OER activity. ${ }^{22,28}$ 
On the other hand, the structural transformation of the cobalt-based catalyst during electrochemical HER has mostly been investigated only by ex situ methods. ${ }^{16,29-31}$ The ex situ methods have various drawbacks including the oxidation of the precatalysts in alkaline conditions and the possible surface oxidation of the active phase in aerial conditions. ${ }^{5}$ Therefore, it is highly desirable to investigate the active catalyst structure through in situ methods.

Though a series of cobalt (oxide) phosphate-based catalysts have been explored for the $\mathrm{OER}^{16,20-24,26,27}$ and HER, ${ }^{16,29,30,32-34}$ their use for the overall water splitting is fostered in the last few years. Cobo et al. have developed a Janus cobalt-based catalyst for the OER and HER at neutral $\mathrm{pH} .{ }^{35}$ The catalyst showed the formation of metallic Co coated with a cobalt-oxo/hydroxophosphate during HER in neutral medium. ${ }^{35}$ Recently, we reported helical cobalt borophosphates for the electrochemical water splitting in the alkaline medium where the structural transformation of the catalyst at the anode and cathode was observed to attain two different active catalyst structures. ${ }^{36}$ Therefore, understanding the structural transformation and realizing the structure of such active catalysts for both HER and OER is of fundamental interest to establish the structureactivity correlation.

Here we report a new class of material: cobalt phosphonate (CoPn) for electrochemical water splitting in alkaline medium. Phosphonates coordinate to the metal ion through the oxygen atoms and the reaction conditions significantly affect the local environment of the coordination around the metal centers (Fig. S1†). ${ }^{37}$ Though these inorganic-organic hybrid materials are known for a long time, their applications for the photochemical and electrochemical water oxidation have been explored only recently. ${ }^{38-42}$ Inspired by the excellent photochemical as well as electrochemical water oxidation of the phosphonates, ${ }^{\mathbf{3 8 - 4 2}}$ we have prepared CoPn and employed for the unification of electrochemical water oxidation, proton reduction, and overall water splitting. The nickel foam (NF) supported CoPn produced excellent OER activity in an alkaline medium to reach the current density of $10 \mathrm{~mA} \mathrm{~cm}{ }^{-2}$ at only $240 \mathrm{mV}$ overpotential whereas an overpotential of $144 \mathrm{mV}$ was required for HER to attain the same current density. In addition, the designed alkaline overall watersplitting device displayed a cell voltage of only $1.62 \mathrm{~V}$ to reach the current density $10 \mathrm{~mA} \mathrm{~cm} \mathrm{~cm}^{-2}$, making it one of the promising materials towards efficient water splitting. Further, the structural insights gathered from quasi in situ and ex situ experiments revealed that with applied potential CoPn transformed into a layered Co oxide structure, related to the crystalline $\mathrm{LiCoO}_{2}$ or crystalline $\mathrm{CoO}(\mathrm{OH})$ but with clearly lower degree of order during OER whereas the HER catalyst comprises of metallic cobalt, $\mathrm{Co}_{3} \mathrm{O}_{4}$ and $\mathrm{Co}(\mathrm{OH})_{2}$.

\section{Results and discussion}

CoPn was synthesized by the solvothermal reaction of $\mathrm{Co}\left(\mathrm{NO}_{3}\right)_{2} \cdot 6 \mathrm{H}_{2} \mathrm{O}$ and diethylenetriamine penta(methylenephosphonic acid) [DTPMP] (see the details in Experimental in $\mathrm{ESI}_{\dagger}^{\dagger}$ ). The material was purely amorphous in nature as revealed by the powder X-ray diffraction (Fig. S2 $\dagger$ ). Infrared spectrum detects the corresponding vibrations related to CoPn, as discussed in detail in the ESI (Fig. S3 $\dagger$ ). ${ }^{43}$ The amorphous structure of the particles was clearly visible by the transmission electron microscopic (TEM) studies (Fig. 1). High-resolution TEM could not detect any lattices, whereas the selected area diffraction pattern (SAED) also revealed the amorphous nature of the CoPn particles (Fig. 1). Energy dispersive X-ray (EDX) detects the presence of Co, N, and P in fresh CoPn (Fig. S4 $\dagger$ ). The elemental analysis reveals that the ratio $\mathrm{C} / \mathrm{N} \sim 2.83$ in CoPn (close to the theoretical value of $\mathrm{C} / \mathrm{N}=9 / 3=3$ ).

The surface properties, oxidation state and surface composition of CoPn were analyzed by X-ray photoelectron spectroscopic (XPS) studies (Fig. S5†). In Co 2p XPS, two peaks corresponding to Co $2 \mathrm{p}_{1 / 2}$ and Co $2 \mathrm{p}_{3 / 2}$ appeared at the binding energies of $\sim 797 \mathrm{eV}$ and $\sim 781 \mathrm{eV}$, respectively (Fig. S5a $\dagger$ ). The spin-orbit coupling spacing value $\left(2 \mathrm{p}_{3 / 2}-2 \mathrm{p}_{1 / 2}\right)$ of $15.96 \mathrm{eV}$ indicates $\mathrm{Co}^{\mathrm{II}}$ as the dominant species. ${ }^{\mathbf{1 4 1 5}}$ The $\mathrm{O} 1 \mathrm{~s}$ signal of pristine CoPn showed two peaks (531.2 eV and $532.0 \mathrm{eV}$ ) corresponding to $\mathrm{P}-\mathrm{O}-\mathrm{Co}$ linkages and oxygen from water (Fig. S5b $\dagger$ ). ${ }^{43}$ The $\mathrm{N}$ 1s peak can also be deconvoluted into two peaks at $399.9 \mathrm{eV}$ and $401.8 \mathrm{eV}$ indicating the $\mathrm{C}-\mathrm{N}$-containing moiety and quarternary $\mathrm{N}$ (Fig. S5c $\dagger$ ). ${ }^{43}$ The $\mathrm{P} 2 \mathrm{p}$ peaks at binding energy $133.4 \mathrm{eV}\left(2 \mathrm{p}_{3 / 2}\right)$ and $134.3 \mathrm{eV}\left(2 \mathrm{p}_{3 / 2}\right)$ indicate the presence of $\mathrm{PO}_{x}$ unit in the phosphonate and clearly matched with the literature reports (Fig. S5d $\dagger$ ). ${ }^{43}$

The as-prepared CoPn was first deposited on nickel foam (NF) by electrophoretic deposition (EPD) and electrochemical performances were investigated in $1 \mathrm{M}$ aqueous $\mathrm{KOH}$ solution by a typical three-electrode system. For comparison, the OER properties of bare NF and commercially available benchmark electrocatalysts were also studied under the same condition. As presented in Fig. 2a, CoPn/NF exhibited an excellent OER activity with an overpotential of $240 \mathrm{mV}$ to drive geometrical catalytic current density of $10 \mathrm{~mA} \mathrm{~cm}^{-2}(330 \mathrm{mV}$ at $100 \mathrm{~mA}$ $\mathrm{cm}^{-2}$ ). The potential is significantly lower than noble metal catalysts $\mathrm{RuO}_{2} / \mathrm{NF}, \mathrm{IrO}_{2} / \mathrm{NF}$, and NF. Interestingly, the achieved current density and overpotentials for CoPn was also found to be comparable to recently reported NF supported transition metal catalysts (Table $\mathrm{S} 1 \dagger$ ). ${ }^{\mathbf{4 4 - 4 6}}$

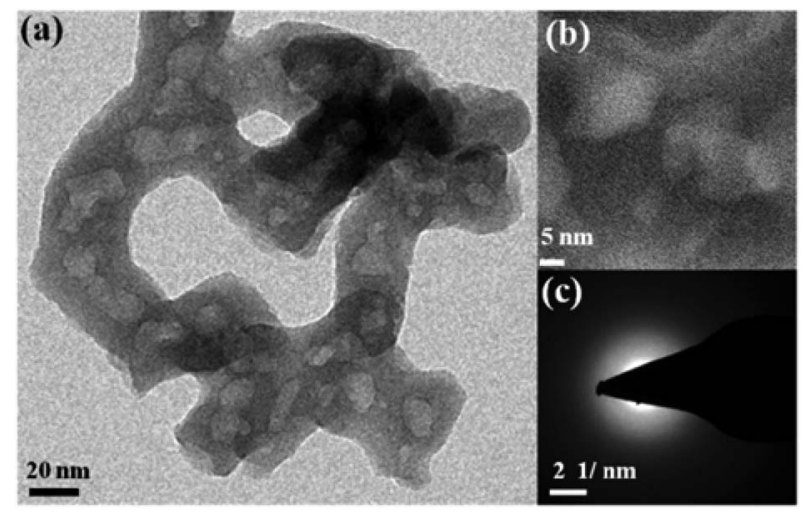

Fig. 1 (a) TEM image of CoPn, (b) high-resolution TEM image of CoPn and $(c)$ electron diffraction pattern representing the amorphous nature of the material. 

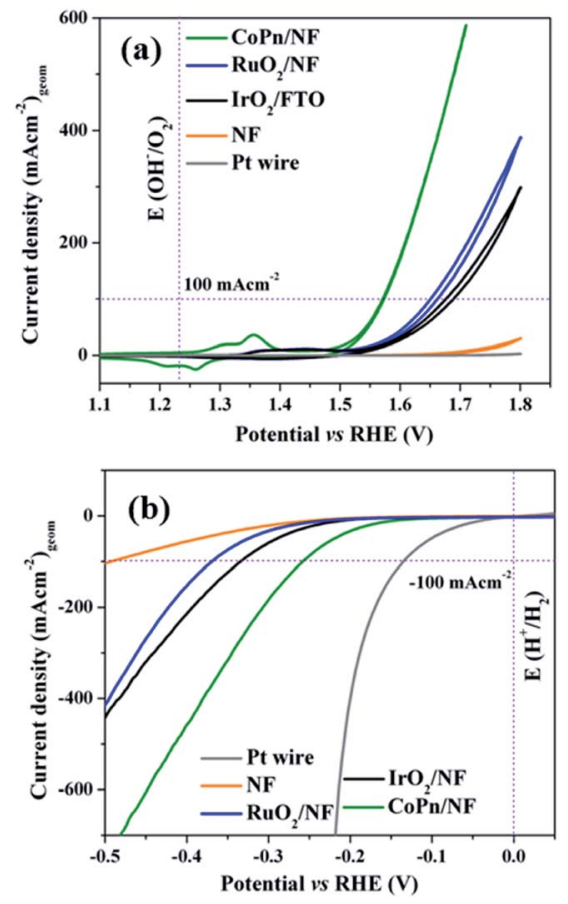

Fig. 2 (a) CV of OER and (b) LSV of HER for CoPn/NF and commercial noble metal-based catalysts in $1 \mathrm{M}$ aqueous $\mathrm{KOH}$ at a scan rate of $1 \mathrm{mV}$ $\mathrm{s}^{-1}$.

To further illustrate the superior catalytic performance, the electrochemical impedance spectroscopy (EIS) was conducted where the Nyquist plots revealed very low charge-transfer resistance $\left(R_{\mathrm{ct}}\right)$ for CoPn/NF suggesting faster electron transfer rate between the interface of the catalyst that contributes to the higher OER activity (Fig. S6†). ${ }^{47}$ The electrochemical doublelayer capacitance $\left(C_{\mathrm{dl}}\right)$ was determined by cyclic voltammetry (CV) in the non-faradic reaction range (Fig. S9†). A $C_{\mathrm{dl}}$ of 2.14 $\mathrm{mF} \mathrm{cm}^{-2}$ was achieved for CoPn/NF that was almost thrice larger compared to bare $\mathrm{NF}\left(0.8 \mathrm{mF} \mathrm{cm}{ }^{-2}\right) .{ }^{48}$ The $C_{\mathrm{dl}}$ was then converted into ECSA using the specific capacitance $\left(C_{\mathrm{s}}\right)$ of the material per unit area $\left(C_{\mathrm{s}}=1.7 \mathrm{mF} \mathrm{cm}^{-2}\right.$ for $\left.\mathrm{NF}\right),{ }^{47}$ and a value of $1.25 \mathrm{~cm}^{2}$ (for details see Fig. $\mathrm{S} 7 \dagger$ and Experimental section) was estimated for $\mathrm{CoPn} / \mathrm{NF}$ demonstrating the presence of rich catalytically active sites than that of NF $\left(0.47 \mathrm{~cm}^{2}\right) .{ }^{49}$

Two redox peaks were detected while cycling CoPn/NF between the potential values of $1.15 \mathrm{~V}$ and $1.45 \mathrm{~V} v s$. RHE (Fig. S8 $\dagger$ ). These two peaks represent the oxidation of $\mathrm{Co}^{\mathrm{II}}$ to $\mathrm{Co}^{\mathrm{III}}$ and $\mathrm{Co}^{\mathrm{IV}}$ during the electrochemical process to form active OER catalyst $\mathrm{CoO}_{x}(\mathrm{OH})_{y} .{ }^{50}$ The confirmation of the increase in the oxidation state was further proved by the ex situ XPS and quasi in situ X-ray absorption spectroscopic (XAS) studies (see later). Tafel plots assessed the catalytic reaction kinetics of

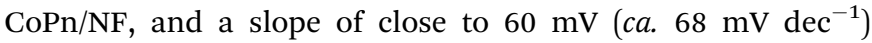
indicates that the OER mechanism proceeds through reversible electron transfer before reaching the turnover-limiting step (Fig. S9†). ${ }^{51}$ Moreover, the excellent stability of the system has been achieved to show constant current production for more than $25 \mathrm{~h}$ under chronoamperometric (CA) conditions (Fig. S10†). A careful investigation of the CA profile reveals that there was a significant increment in the current density within the first $12 \mathrm{~h}$. The initial increase in the current density can be explained by the activation of the precatalyst ( $\mathrm{CoPn}$ ) to form the active water oxidation catalyst. As the transformation of the precatalyst to active catalyst was completed, a slight drop in current density was observed, indicating slow deactivation of the catalyst on longer run.

Similarly, the NF supported CoPn has been tested for HER in $1 \mathrm{M}$ aqueous $\mathrm{KOH}$ solution. Only $144 \mathrm{mV}$ of overpotential was required to achieve a current density of $10 \mathrm{~mA} \mathrm{~cm}^{-2}$ (Fig. 2b). Similar to OER catalysis, the catalytic HER performance of CoPn is better than the noble metal-based catalysts and bare NF but inferior to Pt. The activity of CoPn is also comparable to recently reported transition metal-based catalysts (Table S2 $\dagger$ ). A constant current was recorded to produce $\mathrm{H}_{2}$ over $25 \mathrm{~h}$ under chronoamperometric conditions (Fig. S11†).

As most of the cobalt-based transition metal catalysts are transformed into $\mathrm{CoO}_{x}(\mathrm{OH})_{y}$ during OER in alkaline medium, ${ }^{26,31,36,50}$ we have extensively carried out studies on the structural transformation of CoPn. First, the catalyst was characterized by ex situ spectroscopic, microscopic and analytical methods after $25 \mathrm{~h} \mathrm{CA}$ measurements. Destruction of the structure of the CoPn was detected by TEM studies (Fig. 3). A layered structure with overlapping plates was formed after the OER (Fig. $3 \mathrm{a}$ and b). The rings of the SAED could be attributed to the (110) and (130) planes of the $\mathrm{Co}(\mathrm{O}) \mathrm{OH}$ (JCPDF: 26-480). Similarly, CoPn also underwent complete transformation after HER-CA displaying rings of (220) (311) and (511) corresponding to the spinel $\mathrm{Co}_{3} \mathrm{O}_{4}$ phase (JCPDF: 42-1467) (Fig. 3c and d).

The XPS studies revealed that the oxidation state of Co was increased after the oxygen evolution (Fig. 4 and S12 $\dagger$ ). From the literature, it is well known that $\mathrm{Co}^{\mathrm{II}}$ and $\mathrm{Co}^{\mathrm{III}}$ ions have almost similar $2 \mathrm{p}$ binding energies (BE) but can be differentiated by the

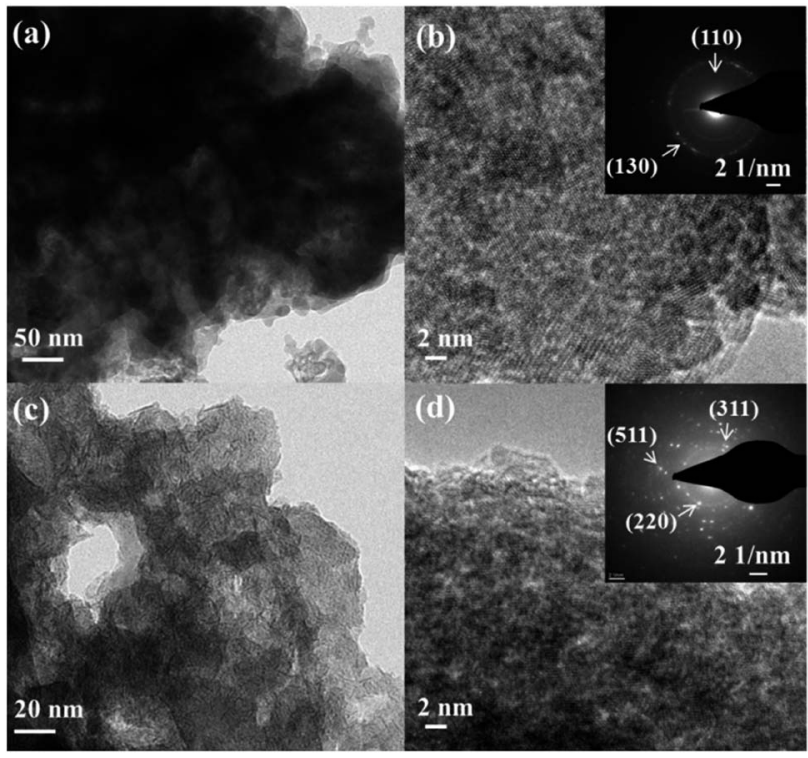

Fig. 3 TEM and HR-TEM images of CoPn after chronoamperometric OER ( $a$ and $b$ ) and HER ( $c$ and d) studies in $1 \mathrm{M}$ alkaline $\mathrm{KOH}$ solution. The corresponding electron diffraction pattern is shown in the inset. 


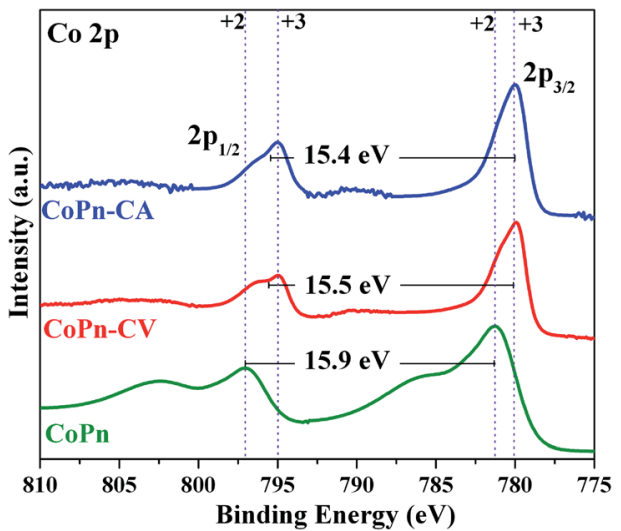

Fig. 4 Comparison of the Co $2 p$ XPS spectra in pristine form and after OER-CV and OER-CA. As the binding energies of Co" and Co"I' sites are not unambiguous, they can be further differentiated by the Co $2 p_{1 / 2}-2 p_{3 / 2}$ spin-orbit level energy spacing. The difference of $16.0 \mathrm{eV}$ represents high-spin Co" whereas 15.0 eV comprises low-spin Co"I. The oxidation of Co" to Co" during OER is reflected in the decreased spin-orbit coupling values.

Co $2 \mathrm{p}_{1 / 2}-2 \mathrm{p}_{3 / 2}$ spin-orbit coupling value, which is $16 \mathrm{eV}$ for high-spin $\mathrm{Co}^{\mathrm{II}}$ and $15 \mathrm{eV}$ for low spin $\mathrm{Co}^{\mathrm{III}} \cdot{ }^{17}$ An energy spacing of $15.5 \mathrm{eV}$ was attained after OER CV that indicated the presence of mixed-valent $\mathrm{Co}^{\mathrm{II}}-\mathrm{Co}^{\mathrm{III}}$ species. Moreover, after OER CA, the energy spacing was further reduced to $15.5 \mathrm{eV}$, which clearly confirmed the dominant amount of $\mathrm{Co}^{\mathrm{III}}$ species. ${ }^{17}$ The deconvolution of the Co $2 \mathrm{p}$ peaks also indicates the oxidation of $\mathrm{Co}^{\mathrm{II}}$ to $\mathrm{Co}^{\mathrm{III}}$ during the electrochemical process. ${ }^{36}$ After the electrochemical measurements (both $\mathrm{CV}$ and $\mathrm{CA}$ ), the $\mathrm{O}$ 1s peak was deconvoluted into three peaks. As anticipated, the peak corresponding to $\mathrm{P}-\mathrm{O}-\mathrm{Co}$ species was disappeared with the formation of the new peak for Co-O bonds $(529.5 \mathrm{eV})$ from Co-oxide/ hydroxide species (Fig. S13 $\dagger$ ). ${ }^{\mathbf{2 6 , 5 0}}$ The other two deconvoluted peaks of $\mathrm{O} 1 \mathrm{~s}$ indicate substantial hydration (532.7-533.6 eV) and hydroxylation $(531.4 \mathrm{eV})$ of the catalyst surface during electrochemical OER. ${ }^{26,50}$ The signals from $\mathrm{N}$ and $\mathrm{P}$ in pristine CoPn were also disappeared after alkaline water oxidation (Fig. S14 and S15 $\dagger$ ). More detailed descriptions of the deconvoluted spectra are given in Fig. S12 to S15 of ESI. $\dagger$

Similarly, the catalyst at the cathode was also characterized after HER CV and CA by XPS. The Co $2 \mathrm{p}_{1 / 2}-2 \mathrm{p}_{3 / 2}$ spin-orbit coupling value was calculated to be $15.5 \mathrm{eV}$ after HER CV and $15.4 \mathrm{eV}$ after CA, showing the formation of mixed valent $\mathrm{Co}^{\mathrm{II}}$ $\mathrm{Co}^{\mathrm{III}}$ species (Fig. S16 $\dagger$ ). ${ }^{36}$ The structural transformation of CoPn during HER was further confirmed from the $\mathrm{O}$ 1s spectra where the $\mathrm{P}-\mathrm{O}-\mathrm{Co}$ bridge was not detected. Instead, a new peak appeared at $529.5 \mathrm{eV}$ for $\mathrm{Co}-\mathrm{O}$ bonds (Fig. S17†). ${ }^{36}$ Like in the case of OER, a significant amount of hydration (532.5 eV and $533.6 \mathrm{eV}$ ) of the catalyst was detected after HER. ${ }^{\mathbf{1 4 , 2 4 , 3 1}}$ The signal from $\mathrm{P}$ was also absent after HER confirming severe structural transformation at the cathode (Fig. S18†). ${ }^{24}$ From XPS, it was clear that CoPn acts as the precatalyst and completely transformed into a combination of distinct active structures at the cathode and anode during electrochemical water splitting. Moreover, the transformation occurred within the first CV measurement where a loss of over 90\% phosphorous was attained, which was confirmed by the ICP-AES studies.

To have a more conclusive understanding of the structural transformation of CoPn during water oxidation with varying potential (CV) and at a constant potential (CA) quasi in situ Co K edge, X-ray absorption near edge spectroscopic (XANES) studies were carried out (Fig. 5). The XANES edge shape clearly revealed the structure of as-prepared CoPn remains intact even after EPD on the electrode, which is also consistent with the EXAFS spectra (Fig. S19 and Table S3†). After cycling (CV) and at CA relevant to OER, pronounced structural transformations were attained. The transformation was fast, and the structure of the catalyst after CV or CA at OER potentials was virtually the same (Fig. 4). The edge shape after OER resembles the one from amorphous layered oxides (CoCat) electrodeposited by Nocera's group (Fig. S20†). ${ }^{27,52}$ This converted structure can be derived from the $\mathrm{LiCoO}_{2}$ crystal structure, but in the present case, as well as in the catalysts from the group of Nocera, the edge was rather smooth and non-structured, a clear indication of the disordered structure of the catalyst. The simulation of the edge shape as a linear combination of spectra was difficult due to the amorphous character of the CoCat (lack of a well-defined crystal structure) and due to the known redox-activity of the Co ions in the structure, which does affect the edge position (the edge position will depend on the history of the applied potential).

To draw a further conclusion on the structure of the catalyst at OER potentials, we performed EXAFS simulations (Fig. 6 and S21 $\dagger$ ). First, we used an unbiased simulation approach to identify possible structures besides the layered CoCat of Nocera type. Evidence for the presence of other structures was ascertained by the appearance of the shoulder at the right side of the second FT peak (Fig. 6). This first simulation approach (Table $\mathrm{S} 4 \dagger$ ) indicated the possible presence of a spinel structure in the catalyst. To determine the percentage of the spinel structure, we repeated the simulation assuming a combination of ideal, crystalline spinel and ideal layered Co oxide (simulation approach 2 in Table $\mathrm{S} 4 \dagger)$. The results suggested that there is about $20 \%$ of spinel structure in the OER catalysts.

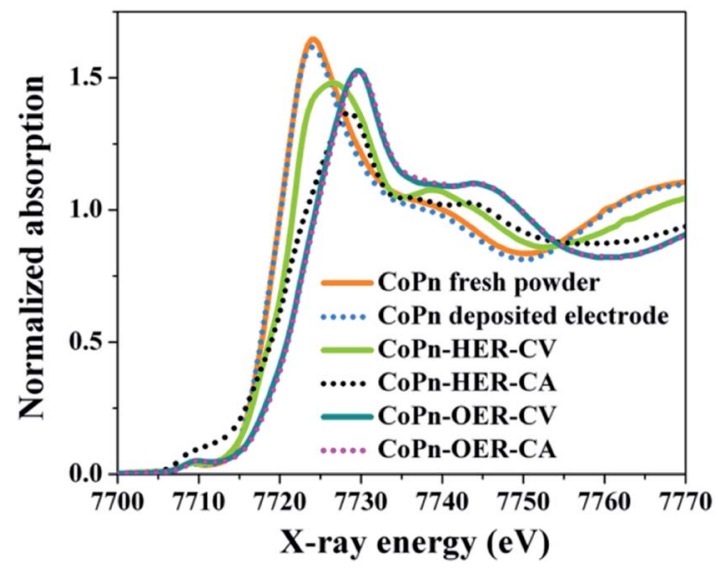

Fig. 5 In situ XANES Co K-edge spectra are showing the change in the oxidation state of Co from fresh CoPn during alkaline OER and HER at a constant potential (CA) as well as varying potential (CV). 


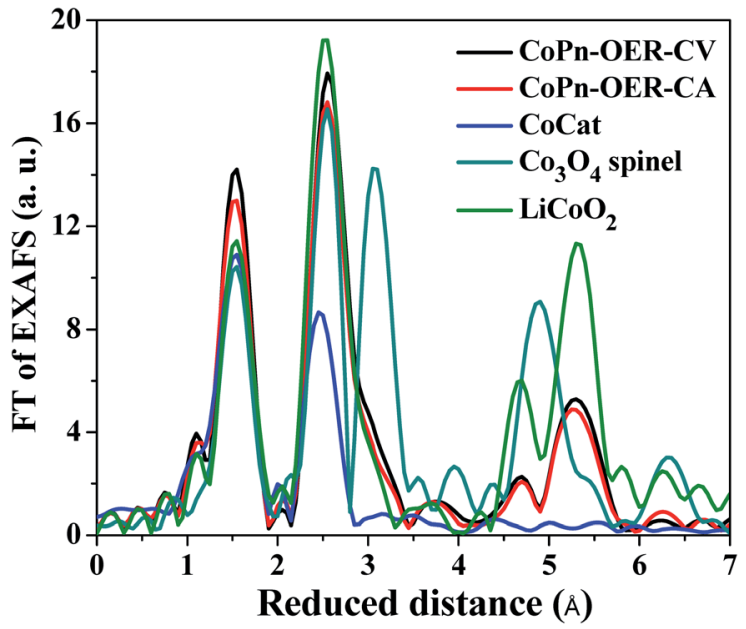

Fig. 6 FT of EXAFS of CoPn exposed to OER potentials compared with other catalysts. Two approaches to simulations are shown in Table $\mathrm{S} 4 . \dagger$ Please note that $\mathrm{LiCOO}_{2}$ is isostructural to $\mathrm{CoOOH}$ resulting in indistinguishable EXAFS spectra.

In the case of HER, the edge shape significantly changed (Fig. 4) after both CV and CA. The transformation was much slower after $\mathrm{CV}$, and the changes were more pronounced after CA. To understand how these changes related to structural transformation, we simulated the edge spectra after CV and CA as a linear combination of edge spectra of some reference compounds (Fig. S22 $\dagger$ ). The results show that in both cases, the starting compound is destroyed. The spectrum after $\mathrm{CV}$ (Fig. S22a $\dagger$ ) can be modeled as a linear combination of $38 \%$ hydrated $\mathrm{Co}^{2+}$ ions and $62 \%$ Co spinel structure $\left(\mathrm{Co}_{3} \mathrm{O}_{4}\right)$. The spectrum after CA can be described as a linear combination of $4 \% \mathrm{Co}^{2+}$ ions, 91\% Co spinel structure, and 5\% contribution from a metallic Co (Fig. S22b $\dagger$ ). In our previous report with cobalt borophosphates, ${ }^{36}$ we also detected the formation of $\mathrm{Co}^{0}$ during HER, where favorable adsorption of water and proton on cobalt surface as well as the facile desorption of the intermediates from the surface was ascribed to be the reason for the enhancement in HER activity. ${ }^{53,54}$ In fact, the local environment around the $\mathrm{Co}^{0}$ plays a major role in controlling the Gibbs free energy of adsorption. For example, in the Janus $\mathrm{H}_{2}$-Cat, $\mathrm{Co}^{0}$ species encapsulated in the $\mathrm{Co}(\mathrm{OH})_{2}$ shell provides the active sites for HER, while the N-doped carbon significantly lowers the adsorption free energy in Co@NC. ${ }^{3,53,54}$ Therefore, in the present case, we propose the participation of $\mathrm{Co}^{\circ}$ along with $\mathrm{Co}(\mathrm{OH})_{2} / \mathrm{Co}_{3} \mathrm{O}_{4}$ species are responsible for the efficient alkaline HER.

This edge-shape simulation, especially, in the case of the catalyst after CA is not perfect. The reason can be that the spinel structure in the resulting material is non-crystalline, e.g., the tetrahedral sites in the spinel structure are not $100 \%$ occupied and the number of mono- $\mu$-oxo bridges between the Co atoms is lower than predicted. Additional insights into the structure of these materials can be obtained from the simulations of EXAFS spectra (Fig. S23 $\dagger$ ). In the simulation of the EXAFS spectrum of the catalyst after CV appears an additional Co-Co distance of
$3.16 \AA$ (Table $\mathrm{S} 5 \dagger$ ) which is not typical for the spinel structure. This distance suggests the presence of structural motifs of a third phase, for example, $\mathrm{Co}_{5}(\mathrm{OH})_{4}(\mathrm{POH})_{2}$ or $\mathrm{Co}(\mathrm{OH})_{2}$.

To verify the cooperative effect of different true active structures involved in OER and HER catalysis, we synthesized the individual components of active structure present in CoPn during OER $\left(\mathrm{CoOOH}, \mathrm{Co}_{3} \mathrm{O}_{4}, \mathrm{Co}(\mathrm{OH})_{2}\right)$ and $\mathrm{HER}\left(\mathrm{Co}_{3} \mathrm{O}_{4}\right.$, Co and $\mathrm{Co}(\mathrm{OH})_{2}$ ) and tested in a similar fashion to that of CoPn in $1 \mathrm{M}$ aqueous $\mathrm{KOH}$ solution (see Experimental section). When compared, surprisingly, the CoPn exhibited much superior activity in both HER and OER, signifying the importance of the collective components of the active structures over a single constituent (Fig. S24 and S25†).

The excellent performance of CoPn as the bifunctional catalyst led us to construct a two-electrode system by employing NF supported CoPn as the anode and cathode. The overall water splitting reaches a current density of $10 \mathrm{~mA} \mathrm{~cm}^{-2}$ at only $1.62 \mathrm{~V}$ (Fig. S26†). Besides, excellent long-term stability of $25 \mathrm{~h}$ was established for CoPn/NF, representing it as one of the most competent catalytic systems for alkaline water electrolysis (Fig. S27†).

\section{Conclusions}

For the first time, we have demonstrated that cobalt phosphonate is a new class of highly active pre-catalysts for overall water splitting in alkaline media. Remarkably, it acts as a dual precursor for OER and HER: (i) under OER conditions, pristine cobalt phosphonate is transformed into layered Co oxides (CoCat) similar to crystalline $\mathrm{CoO}(\mathrm{OH})$ but with a lower degree of order to facilitate OER, while (ii) under HER conditions, metallic Co is produced as active species for $\mathrm{H}_{2}$ production which is promoted by the presence of spinel $\mathrm{Co}_{3} \mathrm{O}_{4}$ and $\mathrm{Co}(\mathrm{OH})_{2}$. The bifunctionality of the (pre)catalyst was further explored for overall water splitting that showed a very low cell voltage with high durability. Our investigation revealed new insights into the evolution and complex nature of interface structures to achieve highly efficient and durable overall watersplitting electrocatalysts, originating from the same metalphosphorus-containing single-source precursor.

\section{Conflicts of interest}

There are no conflicts to declare.

\section{Acknowledgements}

Funded by the Deutsche Forschungsgemeinschaft (DFG, German Research Foundation) under Germany's Excellence Strategy - EXC 2008/1 - 390540038. Gefördert durch die Deutsche Forschungsgemeinschaft (DFG) im Rahmen der Exzellenzstrategie des Bundes und der Länder - EXC 2008/1 390540038. A. I. acknowledges the financial support from CSIR [grant no. 01(2977)/19/EMR-II], India. The authors are indebted to Dr Vitaly Gutkin for XPS measurements. 


\section{Notes and references}

1 I. Roger, M. A. Shipman and M. D. Symes, Nat. Rev. Chem., 2017, 1, 0003.

2 C. Panda, P. W. Menezes and M. Driess, Angew. Chem., Int. Ed., 2018, 57, 11130-11139.

3 F. Yu, L. Yu, I. K. Mishra, Y. Yu, Z. F. Ren and H. Q. Zhou, Materials Today Physics, 2018, 7, 121-138.

4 (a) M.-I. Jamesh, Y. Kuang and X. Sun, ChemCatChem, 2019, 11, 1550-1575; (b) Y. Zhu, H.-C. Chen, C.-S. Hsu, T.-S. Lin, C.-J. Chang, S.-C. Chang, L.-D. Tsai and H. M. Chen, ACS Energy Lett., 2019, 4, 987-994.

5 C. Panda, P. W. Menezes, M. Zheng, S. Orthmann and M. Driess, ACS Energy Lett., 2019, 4, 747-754.

6 N. T. Suen, S. F. Hung, Q. Quan, N. Zhang, Y. J. Xu and H. M. Chen, Chem. Soc. Rev., 2017, 46, 337-365.

7 H. Dau, C. Limberg, T. Reier, M. Risch, S. Roggan and P. Strasser, ChemCatChem, 2010, 2, 724-761.

8 H. M. Xu, S. Q. Ci, Y. C. Ding, G. X. Wang and Z. H. Wen, J. Mater. Chem. A, 2019, 7, 8006-8029.

9 T. Reier, M. Oezaslan and P. Strasser, ACS Catal., 2012, 2, 1765-1772.

10 Y. Jiao, Y. Zheng, M. T. Jaroniec and S. Z. Qiao, Chem. Soc. Rev., 2015, 44, 2060-2086.

11 B. You and Y. J. Sun, Acc. Chem. Res., 2018, 1, 1571-1580.

12 F. L. Lyu, Q. F. Wang, S. M. Choi and Y. D. Yin, Small, 2019, 15, 1804201.

13 K. N. Dinh, Q. H. Liang, C. F. Du, J. Zhao, A. L. Y. Tok, H. Mao and Q. Y. Yan, Nano Today, 2019, 25, 99-121.

14 X. H. Deng and H. Tuysuz, ACS Catal., 2014, 4, 3701-3714.

15 A. Bergmann, E. Martinez-Moreno, D. Teschner, P. Chernev, M. Gliech, J. F. de Araujo, T. Reier, H. Dau and P. Strasser, Nat. Commun., 2015, 6, 8625.

16 H. H. Zhong, C. A. Campos-Roldan, Y. Zhao, S. W. Zhang, Y. J. Feng and N. Alonso-Vante, Catalysts, 2018, 8, 559.

17 P. W. Menezes, A. Indra, D. Gonzalez-Flores, N. R. Sahraie, I. Zaharieva, M. Schwarze, P. Strasser, H. Dau and M. Driess, ACS Catal., 2015, 5, 2017-2027.

18 M. W. Kanan and D. G. Nocera, Science, 2008, 321, 10721075.

19 M. W. Kanan, Y. Surendranath and D. G. Nocera, Chem. Soc. Rev., 2009, 38, 109-114.

20 H. S. Ahn and T. D. Tilley, Adv. Funct. Mater., 2013, 23, 227233.

21 D. Gonzalez-Flores, I. Sanchez, I. Zaharieva, K. Klingan, J. Heidkamp, P. Chernev, P. W. Menezes, M. Driess, H. Dau and M. L. Montero, Angew. Chem., Int. Ed., 2015, 54, 2472-2476.

22 Y. Y. Liu, H. T. Wang, D. C. Lin, C. Liu, P. C. Hsu, W. Liu, W. Chen and Y. Cui, Energy Environ. Sci., 2015, 8, 1719-1724.

23 J. Wang and H. C. Zengg, ACS Appl. Mater. Interfaces, 2018, 10, 6288-6298.

24 P. W. Menezes, C. Panda, C. Walter, M. Schwarze and M. Driess, Adv. Funct. Mater., 2019, 1808632.

25 F. Song, L. C. Bai, A. Moysiadou, S. Lee, C. Hu, L. Liardet and X. L. Hu, J. Am. Chem. Soc., 2018, 140, 7748-7759.
26 P. W. Menezes, A. Indra, V. Gutkin and M. Driess, Chem. Commun., 2017, 53, 8018-8021.

27 M. Risch, F. Ringleb, M. Kohlhoff, P. Bogdanoff, P. Chernev, I. Zaharieva and H. Dau, Energy Environ. Sci., 2015, 8, 661674.

28 H. Kim, J. Park, I. Park, K. Jin, S. E. Jerng, S. H. Kim, K. T. Nam and K. Kang, Nat. Commun., 2015, 6, 8253.

29 L. Su, X. Z. Cui, T. He, L. M. Zeng, H. Tian, Y. L. Song, K. Qi and B. Y. Xia, Chem. Sci., 2019, 10, 2019-2024.

30 G. Q. Zhao, K. Rui, S. X. Dou and W. P. Sun, Adv. Funct. Mater., 2018, 28, 1803291.

31 P. W. Menezes, C. Panda, S. Garai, C. Walter, A. Guiet and M. Driess, Angew. Chem., Int. Ed., 2018, 57, 15237-15242.

32 J. Wang, H. X. Zhong, Z. L. Wang, F. L. Meng and X. B. Zhang, ACS Nano, 2016, 10, 2342-2348.

33 Z. F. Dai, H. B. Geng, J. Wang, Y. B. Luo, B. Li, Y. Zong, J. Yang, Y. Y. Guo, Y. Zheng, X. Wang and Q. Y. Yan, ACS Nano, 2017, 11, 11031-11040.

34 M. Caban-Acevedo, M. L. Stone, J. R. Schmidt, J. G. Thomas, Q. Ding, H. C. Chang, M. L. Tsai, J. H. He and S. Jin, Nat. Mater., 2015, 14, 1245-1251.

35 S. Cobo, J. Heidkamp, P. A. Jacques, J. Fize, V. Fourmond, L. Guetaz, B. Jousselme, V. Ivanova, H. Dau, S. Palacin, M. Fontecave and V. Artero, Nat. Mater., 2012, 11, 802-807.

36 P. W. Menezes, A. Indra, I. Zaharieva, C. Walter, S. Loos, S. Hoffmann, R. Schlogl, H. Dau and M. Driess, Energy Environ. Sci., 2019, 12, 988-999.

37 K. J. Gagnon, H. P. Perry and A. Clearfield, Chem. Rev., 2012, 112, 1034-1054.

38 T. H. Zhou, D. P. Wang, S. C. K. Goh, J. D. Hong, J. Y. Han, J. G. Mao and R. Xu, Energy Environ. Sci., 2015, 8, 526-534.

39 D. Shevchenko, M. F. Anderlund, A. Thapper and S. Styring, Energy Environ. Sci., 2011, 4, 1284-1287.

40 R. Zhang, P. A. Russo, A. G. Buzanich, T. Jeon and N. Pinna, Adv. Funct. Mater., 2017, 27, 1703158.

41 T. H. Zhou, Y. H. Du, D. P. Wang, S. M. Yin, W. G. Tu, Z. Chen, A. Borgna and R. Xu, ACS Catal., 2017, 7, 6000-6007.

42 Z. S. Cai, Y. Shi, S. S. Bao, Y. Shen, X. H. Xia and L. M. Zheng, ACS Catal., 2018, 8, 3895-3902.

43 Y. P. Zhu, T. Z. Ren and Z. Y. Yuan, Nanoscale, 2014, 6, 11395-11402.

44 N. K. Chaudhari, H. Jin, B. Kim and K. Lee, Nanoscale, 2017, 9, 12231-12247.

45 F. Lu, M. Zhou, Y. X. Zhou and X. H. Zeng, Small, 2017, 13, 1701931.

46 Y. Wang, B. Kong, D. Y. Zhao, H. T. Wang and C. Selomulya, Nano Today, 2017, 15, 26-55.

47 Q. Kang, L. Vernisse, R. C. Remsing, A. C. Thenuwara, S. L. Shumlas, I. G. McKendry, M. L. Klein, E. Borguet, M. J. Zdilla and D. R. Strongin, J. Am. Chem. Soc., 2017, 139, 1863-1870.

48 C. C. L. McCrory, S. H. Jung, J. C. Peters and T. F. Jaramillo, J. Am. Chem. Soc., 2013, 135, 16977-16987.

49 L. Yu, H. Q. Zhou, J. Y. Sun, F. Qin, F. Yu, J. M. Bao, Y. Yu, S. Chen and Z. F. Ren, Energy Environ. Sci., 2017, 10, 18201827. 
50 A. Indra, P. W. Menezes, C. Das, D. Schmeisser and M. Driess, Chem. Commun., 2017, 53, 8641-8644.

51 Y. Surendranath, M. W. Kanan and D. G. Nocera, J. Am. Chem. Soc., 2010, 132, 16501-16509.

52 M. W. Kanan, J. Yano, Y. Surendranath, M. Dinca, V. K. Yachandra and D. G. Nocera, J. Am. Chem. Soc., 2010, 132, 13692-13701.
53 H. Guo, Q. Feng, J. Zhu, J. Xu, Q. Li, S. Liu, K. Xu, C. Zhang and T. Liu, J. Mater. Chem. A, 2019, 7, 3664-3672.

54 H. Fei, Y. Yang, Z. Peng, G. Ruan, Q. Zhong, L. Li, E. L. G. Samuel and J. M. Tour, ACS Appl. Mater. Interfaces, 2015, 7, 8083-8087. 